\title{
GAMBARAN FUNGSI SEKSUAL DAN KONDISI PSIKOLOGIS PASIEN PENYAKIT GINJAL KRONIS YANG MENJALANI HEMODIALISIS
}

\author{
Raden Siti Jundiah ${ }^{1}$, Sri Wulan Megawati², Rizki Muliani ${ }^{3}$, Nur Intan Husnul \\ Khatimah $^{4}$ \\ 1,2,3,4) Fakultas Keperawatan Universitas Bhakti Kencana \\ siti.jundiah@bku.ac.id
}

\begin{abstract}
ABSTRAK
Hemodialisis memberikan dampak negatif kepada pasien. Disfungsi seksual dan gangguan psikologis adalah gangguan yang umumnya terjadi pada pasien yang menjalani hemodialisis. Gangguan ini sering muncul karena penurunan produktivitas, interaksi sosial yang buruk, serta ketergantungan finansial sebagai akibat dari lamanya terapi yang dijalani pasien. Tujuan penelitian ini adalah untuk mengetahui gambaran fungsi seksual dan psikologis pada pasien penyakit ginjal kronis yang menjalani hemodialisis.. Penelitian ini menggunakan Pendekatan Deskriptif Kuantitatif. Populasi pada penelitian ini adalah pasien penyakit ginjal kronis yang menjalani hemodialisis di Kota Bandung. Sampel pada penelitian ini 36 responden yang diambil dengan menggunakan Teknik Purposive Sampling. Pengambilan data menggunakan Instrumen Arizona Sexual Experience Scale (ASEX) dan subskala psikologis dari Quality of Life Dialysis I. Analisis data menggunakan distribusi frekuensi. Hasil penelitian menggambarkan bahwa 91,7\% mengalami disfungsi seksual dan 94\% merasakan kepuasan yang tinggi pada kondisi psikologisnya. Disfungsi seksual terjadi karena gangguan neurohormonal sehingga aliran darah ke alat kelamin berkurang dan diperburuk oleh tindakan hemodialisis yang dijalani pasien. Pasien memiliki kondisi psikologis yang tinggi dapat disebabkan oleh adaptasi yang baik terhadap hemodialisis dan kepercayaan yang tinggi kepada Tuhan. Hal ini akan berdampak positif terhadap kualitas hidup pasien.
\end{abstract}

Kata kunci : hemodialisis, psikologis, seksual

\section{Abstract}

Hemodialysis hurts patients. Sexual dysfunction and psychological disorders commonly occur in patients undergoing hemodialysis. These disorders often arise due to decreased productivity, poor social interaction, and financial dependency. The purpose of this study is determine of sexual and psychological function in chronic kidney disease patients undergoing hemodialysis. This research uses a descriptive quantitative approach. The population in this study was chronic kidney disease patients who underwent hemodialysis in Bandung. Samples in this study is 36 respondents were taken using purposive sampling. Data retrieval using Arizona Sexual Experience Scale (ASEX) and Psychological Sub Scale of Quality of Life Dialysis I instruments. Data analysis used frequency distribution. The results illustrated that $91.7 \%$ sexual dysfunction and $94 \%$ had a high psychological condition. Sexual dysfunction occurs due to neurohormonal disorders so that blood flow to the genitals is reduced and exacerbated by the hemodialisis actions that the patient undergoes. Patients had high psychological conditions can be caused by good adaptation to hemodialisis and high trust in God. This will have a positive impact on the patient's quality of life.

Keyword: hemodialisis, psychological, sexual 


\section{PENDAHULUAN}

Kidney Disease Improving Global Outcome (KDIGO) mendefinisikan penyakit ginjal kronis adalah kerusakan ginjal yang ditandai adanya proteinuria dan menurunnya Glomerulus Filtration Rate (GFR) yaitu GFR kurang dari 60 $\mathrm{mL} / \mathrm{menit}$, albumin lebih dari $30 \mathrm{mg}$ per gram kreatinin dengan struktur dan fungsi ginjal yang abnormal dalam 3 bulan sedangkan End Stage Kidney Disease (ESKD) jika GFR kurang dari 15 $\mathrm{mL} /$ menit (Onecia, Benyamin, Sarah L, 2019). Prevalensi gagal ginjal kronis di Indonesia pada tahun 2013 menurut (Kemenkes RI, 2017) sebanyak 2 per 1000 penduduk atau 499.800 penduduk. Prevalensi pada laki-laki (0.3\%) lebih tinggi jika dibandingkan dengan perempuan $(0.2 \%)$ sedangkan pasien ESKD yang dirawat dengan hemodialisis secara global menurut (Webster et al., 2017)but current international guidelines define this condition as decreased kidney function shown by glomerular filtration rate (GFR mencapai 280 per 1 juta orang. Pada tahun 2018 di Indonesia menurut (PERNEFRI, 2018), pasien baru gagal ginjal kronis dengan hemodialisis sebanyak 66.433 orang dan pasien aktif sebanyak 132.142 orang sedangkan di Jawa Barat pasien baru sebanyak 14.771 orang dan pasien aktif sebanyak 33.828 orang.

Hemodialisis memberikan dampak yang negatif kepada pasien. Gangguan fungsi seksual adalah gangguan yang umumnya terjadi pada pasien yang menjalani hemodialisis. Penyebab disfungsi seksual multifaktor. Neuropati perifer, berkurangnya respon otonom, penyakit vascular di perifer, terapi farmakologi, uremik, stres fisik, stres psikologi, semua berperan penting dalam kondisi ini (Palmer, BF, Clegg, 2017) Prevalensi gangguan ini 20\%-70\% tergantung dari beratnya penyakit yang dialami pasien (Navaneethan S, Vecchio M, Johnson D, 2010). Gangguan seksual ini penting untuk dikaji karena berdampak pada pasien yang menjalani hemodialisis dan merupakan aspek yang jarang dievaluasi oleh para profesional medis (Holley \& Schmidt, 2010).

Selain gangguan seksual, gangguan psikologi pun sering muncul disebabkan karena produktivitas yang menurun, interaksi sosial yang kurang, ketergantungan finansial sebagai akibat dari lamanya terapi hemodialisis yang dijalani pasien. Pasien terhubung ke mesin hemodialisis selama minimal 2 jam per sesi dengan minimal 3 sesi per minggu. Gangguan psikologis ini berdampak pada kualitas hidup pasien. Ada hubungan negatif antara depresi dengan kualitas hidup pasien yang menjalani hemodialisis di Rumah Sakit Gana. Artinya semakin tinggi tingkat depresi maka semakin rendah kualitas hidup pasien (Ganu et al., 2018). Hasil penelitialain $81,48 \%$ pasien penyakit ginjal kronis yang menjalani hemodialisis mengalami gejala depresi. Gejala yang sering dikeluhkan adalah pasien merasa takut akan nasib dirinya sendiri yang terus- menerus menjalani hemodialisis. Gejala lain yang dirasakan adalah sedih yang diakhiri dengan menangis. Depresi merupakan salah satu gangguan psikologis (Jundiah., 2019).

Tujuan dari penelitian ini adalah 1) untuk mengetahui gambaran karakteristik pasien penyakit ginjal kronis yang menjalani hemodialisis. 2) untuk mengetahui fungsi seksual pada pasien penyakit ginjal kronis yang menjalani hemodialisis. 3) untuk mengetahui gambaran kondisi psikologis pasien penyakit ginjal kronis yang menjalani hemodialisis. Manfaat dari penelitian ini untuk meningkatkan pelayanan asuhan keperawatan kepada pasien.

\section{METODOLOGI}

Penelitian ini menggunakan pendekatan 
deskriptif kuantitatif yaitu penelitian yang bertujuan untuk mendeskripsikan suatu fenomena yang terjadi secara faktual, sistematis dan akurat. Pada penelitian ini peneliti ingin melihat gambaran fungsi seksual dan kondisi psikologis pada pasien penyakit ginjal kronis yang menjalani hemodialisis.

Responden pada penelitian ini adalah pasien penyakit ginjal kronis yang menjalani hemodialisis. Pengambilan sampel pada penelitian ini menggunakan Teknik Purposive Sampling yaitu dengan menggunakan kriteria pasien yang sudah menikah sebelum terapi hemodialisis hingga saat ini. Jumlah sampelnya adalah 36 responden.

Instrumen yang digunakan pada penelitian ini adalah Arizona Sexual Experience Scale (ASEX) dengan nilai reliabilitas 0,9055, digunakan untuk mengidentifikasi fungsi seksual pasien. Instrumen ini terdiri dari 5 pertanyaan. Pertanyaannya adalah seberapa kuat dorongan seks, seberapa mudah terangsang, seberapa mudah mendapatkan dan mempertahankan ereksi bagi laki-laki dan seberapa basah vagina bagi perempuan, seberapa mudah orgasme dan kepuasan saat orgasme. Pilihan jawaban diberi rentang 1-6, dari mulai luar biasa sampai dengan tidak pernah merasakan. Sementara itu untuk mengetahui kondisi psikologis menggunakan pertanyaan subskala psikologis dari instrumen Quality of Life Versi Dialysis I. Nilai reliabilitas instrumen ini berada pada rentang 0.83-0,96 dan nilai reliabilitas untuk subskala psikologis adalah 0,9 . Pertanyaan pada subskala psikologis ini yaitu tentang ketenangan fikiran, kepercayaan kepada Tuhan, penilaian terhadap diri sendiri secara peribadi dan umum, tentang tujuan hidup dan kebahagiaan.

Analisis data untuk mengetahui gambaran fungsi seksual dan kondisi psikologis menggunakan distribusi frekuensi.

\section{HASIL}

\section{Karakteristik Responden}

Tabel 1. Karakteristik Responden

\begin{tabular}{lcc}
\hline \multicolumn{1}{c}{ Karakteristik } & n & \% \\
\hline Jenis Kelamin & & \\
Laki - laki & 20 & 55,6 \\
Perempuan & 16 & 44,4 \\
& & \\
Aktivitas & & \\
Bekerja & 13 & 36,1 \\
Tidak Bekerja & 23 & 63,9 \\
& & \\
Usia & & \\
26-35 & 7 & 19,4 \\
36-45 & 17 & 47,2 \\
46-55 & 7 & 19,4 \\
$>55$ & 5 & 13,9 \\
& & \\
Lama Hemodialisis & & \\
$<6$ bulan & 3 & 8,30 \\
6-1 tahun & 4 & 11,10 \\
$>1$ bulan- $<3$ tahun & 11 & 30,60 \\
$>3$ tahun & 18 & 50,00 \\
\hline
\end{tabular}

Berdasarkan tabel 1. didapatkan hasil lebih dari setengah responden $(55,6 \%)$ berjenis kelamin laki-laki, lebih dari setengahnya $(63,9 \%)$ tidak bekerja, hampir setengahnya $(47,2 \%)$ berada pada rentang usia 36-35 tahun, dan setengah $(50 \%)$ dari responden sudah menjalani hemodialisis lebih dari 3 tahun.

\section{Fungsi Seksual}

Tabel 2. Fungsi Seksual Pasien Penyakit Ginjal yang Menjalani Hemodialisis

\begin{tabular}{|c|c|c|}
\hline $\begin{array}{c}\text { Fungsi } \\
\text { Seksual }\end{array}$ & n & $\%$ \\
\hline Disfungsi & 33 & 91,7 \\
\hline $\begin{array}{l}\text { Tidak } \\
\text { disfungsi }\end{array}$ & 3 & 8,3 \\
\hline
\end{tabular}

Berdasarkan tabel 2. hampir seluruh responden mengalami disfungsi seksual $(91,7 \%)$. 
Tabel 3. Fungsi seksual Pasien Penyakit

Ginjal Kronis Berdasarkan Domain

\begin{tabular}{ll}
\hline Domain & Mean \pm SD \\
\hline Dorongan seks & $3,72 \pm 1,24$ \\
Gairah & $3,42 \pm 1,16$ \\
Ereksi & $3,44 \pm 1,16$ \\
Orgasme & $3,36 \pm 1,35$ \\
Kepuasan orgasme & $3,33 \pm 1,27$ \\
\hline
\end{tabular}

Dari Tabel 3. didapatkan bahwa domain yang paling mengalami disfungsi adalah dorongan seks $(3,72 \pm 1,24)$

\section{Kondisi Psikologis}

Tabel 4. Kondisi Psikologis Pasien Penyakit Ginjal Kronis Yang Menjalani Hemodialisis

\begin{tabular}{lcc}
\hline $\begin{array}{l}\text { Kondisi } \\
\text { Psikologis }\end{array}$ & n & \% \\
\hline Tinggi & 34 & 94 \\
Rendah & 2 & 6 \\
\hline
\end{tabular}

Berdasarkan tabel 4. hampir seluruh (94\%) responden merasakan kepuasan yang tinggi pada kondisi psikologisnya.

Tabel 5. Psikologis Pasien Penyakit Ginjal Kronis Yang Menjalani Hemodialisis

\begin{tabular}{lc}
\hline Domain & Mean \pm SD \\
\hline Ketenangan fikiran & $1,36 \pm 2,72$ \\
Kepercayaan pada Tuhan & $2,43 \pm 0,55$ \\
Pencapaian tujuan hidup & $1,57 \pm 2,16$ \\
Kebahagiaan & $1,72 \pm 1,24$ \\
Penampilan pribadi & $1,97 \pm 1,99$ \\
Penilaian diri & $1,66 \pm 2,28$ \\
\hline
\end{tabular}

Dari tabel 5, didapatkan bahwa kepercayaan kepada Tuhan merupakan domain yang paling tinggi prevalensinya yang dirasakan oleh responden $(2,43)$, dan yang terendah adalah ketenangan fikiran $(1,36)$.

\section{PEMBAHASAN}

Hasil penelitian menggambarkan karakteristik pasien penyakit ginjal kronis lebih dari setengahnya laki-laki, hampir setengahnya $(47,2 \%)$ berusia di rentang 36-45 tahun, lebih dari setengahnya tidak bekerja, dan setengahnya sudah menjalani terapi hemodialisis ini lebih dari 3 tahun. Selanjutnya didapatkan pula bahwa hampir seluruhnya $(91,7 \%)$ pasien penyakit ginjal kronis yang menjalani hemodialisis mengalami disfungsi seksual. Selain itu, hampir seluruhnya (94\%) pasien penyakit ginjal kronik merasakan tingginya kepuasan terhadap kondisi psikologis yang sedang dialaminya.

Pasien penyakit ginjal kronis mengalami gangguan neurohormonal sehingga menyebabkan aliran darah berkurang ke alat genitalia. Hal inilah yang menjadi penyebab terjadinya disfungsi seksual. Kondisi ini di perburuk dengan tindakan hemodialisis yang harus dijalani oleh pasien. Keadaan ini menyebabkan seseorang tidak mampu melakukan aktivitas seksual dan tidak mencapai kepuasan seksual. Pasien merasakan hidupnya tergantung dengan mesin, timbul rasa minder dan tidak mau berinteraksi dengan orang lain. Hal ini sejalan dengan pendapat (Ganu et al., 2018) bahwa lamanya terapi hemodialisis yang dijalani pasien, minimal 2 jam per sesi dengan minimal 3 sesi seminggu menyebabkan pasien mengalami penurunan produktivitas, interaksi sosial yang kurang, dan ketergantungan finansial. Pendapat ini sesuai dengan hasil penelitian bahwa setengah dari responden sudah mengalami terapi hemodialisis lebih dari 3 tahun.

Disfungsi seksual dialami oleh pasien yang menjalani hemodialisis baik laki-laki maupun perempuan tergambar dari hasil penelitian, jumlah persentase diantara keduanya hampir sama, laki-laki 55,6\% dan perempuan 44,4\%. Menurut (Guven et al., 2018), perubahan seksual pada pasien laki-laki diantaranya ditemukan impotensi serta ejakulasi dini dan disfungsi ereksi sedangkan pada perempuan ditemukan adanya penghindaran dan gangguan 
orgasme. Adapun menurut (Kurtulus et al., 2017) seksual pada wanita mengalami perubahan yaitu ditemukannya penurunan hasrat, gairah, pelumasan, orgasme, kepuasan serta rasa nyeri saat berhubungan seksual. Hasil penelitian ini mendukung pendapat penelitian sebelumnya bahwa $91,7 \%$ pasien mengalami disfungsi seksual yaitu adanya penurunan dorongan seks $(3,72 \pm$ $1,24)$, gairah $(3,42 \pm 1,16)$, ereksi $(3,44 \pm 1,16)$, orgasme $(3,36+1,35)$ dan kepuasan orgasme $(3,33 \pm 1,27)$. Dari nilai rata-rata dorongan seks yang paling dirasakan mengalami disfungsi.

Menurut (Manish Rathi, 2012) penyebab disfungsi seksual ini multifaktor. Biasanya merupakankombinasifaktorpsikologis, fisiologis, dan kormobiditas lainnya. Disfungsi ereksi pada pria terutama disebabkan oleh faktor arteri, kebocoran vena, faktor psikologis, neurogenik, endokrin, dan obat-obatan sedangkan disfungsi seksual pada wanita terutama disebabkan oleh faktor hormonal dan bermanifestasi pada ketidakaturan mentruasi, amenorea, kurangnya pelumasan vagina dan kegagalan untuk hamil. Hasil penelitian (Strippoli et al., 2012)"mendele y": \{“formattedCitation":"(Strippoli et al., 2012, $84 \%$ perempuan mengalami disfungsi seksual. Secara independen disfungsi seksual dikaitkan dengan usia, gejala depresi, kurangnya edukasi, menopause, diabetes melitus dan terapi diuretik. Dari $84 \%$ perempuan yang mengalami disfungsi seksual adalah perempuan tua $(61,5 \pm 14,3)$. Adapun pada hasil penelitian menunjukkan $47,2 \%$ berada pada rentang $36-45$ tahun walaupun belum diidentifikasi apakah dari 47,2\% ini yang terbanyak adalah perempuan. Jumlah pasien yang usianya lebih dari 55 tahun berjumlah 19,9\%. Usia merupakan faktor penting yang berkaitan dengan disfungsi seksual pada pasien penyakit ginjal kronik. Usia dihubungkan dengan perubahan fisiologi dan psikologi pada wanita, umumnya terjadi pada masa menopause. Penurunan libido, tingkat kenyamanan, respons seksual, dan frekuensi berhubungan merupakan perubahan fungsi seksual pada wanita. Menurunnya kadar testosteron selama tahap pramenopause menurunkan libido, sensibilitas sentuhan dan kelelahan. Adapun menurut (Vecchio et al., 2012) 83\% laki-laki mengalami disfungsi ereksi $40 \%$ mengalami ereksi yang berat, $36 \%$ ringan hingga sedang. Semua tingkat ereksi secara signifikan berkaitan dengan bertambahnya usia. Penyakit ginjal kronis menyebabkan perubahan dalam beberapa aspek kehidupan, termasuk melakukan peran baru sebagai pasien, pengangguran karena sakitnya, aktivitas sehari-hari yang terbatas dan biaya pengobatan yang mengakibatkan situasi stres yang kompleks. Terapi hemodialisis yang diharapkan mampu mengurangi ancaman dari kematian pada pasien penyakit ginjal kronis juga dapat mengakibatkan tekanan psikologis karena pasien dituntut untuk beradaptasi dengan kondisi yang tidak biasa, keterbatasan dalam kehidupan sehari-hari (Demir et al., 2019). Hasil penelitian yang dilakukan (El-monshed et al., 2020) gangguan psikologis yang muncul akibat hemodialisis yaitu harga diri rendah ketika berhubungan seksual, tidak puas akan fungsi seksualnya. Gejala lain yang dialami adalah hilang harapan, takut akan seks, menyalahkan diri sendiri akan kegagalan seks, dan suasana hati yang tertekan. Selain itu, didapatkan pula bahwa gejala psikologis yang muncul karena adanya kelainan tidur, kehilangan cairan, kehilangan pekerjaan, biaya pengobatan, perubahan gaya hidup, penderitaan karena penyakit, dan gangguan peran dalam keluarga

Gambaran kondisi psikologis pada penelitian ini menggambarkan bahwa kondisi psikologisnya tinggi $(91,7 \%)$. Kondisi psikologis tertinggi pada domain kepercayaan pada Tuhan $(2,43 \pm 0,55)$ dan terendah pada domain ketenangan fikiran $(1,36 \pm 2,72)$. Hasil ini bertentangan dengan hasil penelitian (Elmonshed et al., 2020) bahwa domain ketenangan 
dalam kehidupan, kepercayaan pada Tuhan, pencapaian tujuan hidup, penampilan diri sendiri adalah rendah. Hasil ini juga bertentangan dengan penelitian (Ganu et al., 2018) bahwa gangguan psikologis sering muncul disebabkan karena lamanya terapi hemodialisis yang sudah dijalani oleh pasien, menurunnya produktivitas dan kurangnya interaksi sosial. Pada penelitian ini pasien setengahnya (50\%) sudah menjalani hemodialisis lebih dari 3 tahun dan 63,9\% tidak bekerja. Seharusnya kondisi ini tidak mendukung data psikologis pada penelitian ini. Hal ini mungkin disebabkan karena lamanya hemodialisis menyebabkan pasien sudah beradaptasi terhadap tindakan hemodialisis. Pasien 3 kali dalam seminggu menjalani terapi hemodialisis, bertemu dengan teman sesama pasien, saling berdiskusi bertukar pengalaman walaupun pasien lebih dari setengahnya tidak bekerja, namun interaksi dengan sesama pasien menyebabkan pasien nyaman dan tidak minder. Kondisi ini pun didukung oleh kepercayaan kepada Tuhan yang tinggi yang menurut (Isroin, 2017) menjadikan pasien mudah untuk beradaptasi.

Data penelitian ini memberikan gambaran kepada perawat bahwa dalam memberikan asuhan keperawatan harus dengan pendekatan holistik. Perawat merawat pasien idealnya mempertahankan pandangan holistik yang melibatkan kesadaran akan masalah psikologis, sosial, budaya dan spiritual.

Hasilpenelitianinibelummenggambarkan fungsi seksual dan psikologis secara mendalam sehingga disarankan penelitian selanjutnya menggunakan instrumen yang lebih detail untuk mengukur fungsi seksual dan kondisi psikologis dengan meningkatkan jumlah responden.

\section{SIMPULAN DAN SARAN}

Kesimpulan dari penelitian ini adalah
Hampir seluruh pasien penyakit ginjal kronis yang menjalani hemodialisis mengalami disfungsi seksual dengan disfungsi dorongan seks yang paling tinggi dan hampir seluruh responden mempunyai kondisi psikologis yang tinggi. Dengan domain tertinggi pada kepercayaan kepada Tuhan dan terendah pada ketenangan fikiran. Berdasarkan penelitian ini diharapkan data ini menjadi informasi bagi perawat dalam memberikan asuhan keperawatan dalam memenuhi kebutuhan seksual serta menjadi data dasar untuk penelitian selanjutnnya terkait kualitas hidup pasien penyakit ginjal kronis dengan menggunakan instrument yang lebih detail dan sampel yang lebih banyak.

\section{DAFTAR PUSTAKA}

Demir, M., Canpolat, Ö., Demir, F., Çiçek, S., \& Doğukan, A. (2019). The Effect of Hemodialysis Treatment on Quality of Life and Sleep in Patients with Chronic Kidney Disease. April. https://doi. org/10.5152/turkjnephrol.2019.3380

El-monshed, A. H. E., Mahgoub, N. A., Abdel-baky, H. A., \& Taha, S. M. (2020). Psychosexual Dysfunction and Quality of Life of Hemodialysis Male Patients at Acta Scientific Women's Health ( ISSN : 2582-3205) Psychosexual Dysfunction and Quality of Life of Hemodialysis Male Patients at Mansoura , Egypt. January. https:// doi.org/10.31080/ASWH.2020.02. psychosexual-dysfunction-and-qualityof-life-of-hemodialysis-male-patients-atmansoura-egypt

Ganu, V. J., Boima, V., Adjei, D. N., Yendork, J. S., Dey, I. D., Yorke, E., Mate-Kole, C. C., \& Mate-Kole, M. O. (2018). Depression and quality of life in patients on long term hemodialysis at a nationalhospital in Ghana: a cross-sectional study. Ghana 
Medical Journal, 52(1), 22-28. https:// doi.org/10.4314/gmj.v52i1.5

Guven, S., Sari, F., Inci, A., \& Cetinkaya, R. (2018). Sexual Dysfunction Is Associated with Depression and Anxiety in Patients with Predialytic Chronic Kidney Disease. 75-80. https://doi.org/10.5152/ eurasianjmed.2018.17152

Holley, J. L., \& Schmidt, R. J. (2010). Sexual dysfunction in CKD. American Journal of Kidney Diseases, 56(4), 612-614. https:// doi.org/10.1053/j.ajkd.2010.07.006

Isroin, L. (2017). Adaptasi psikologis pasien yang menjalani hemodialisis. 1(1), 1221.

Jundiah., E. a. (2019). Hubungan Lamanya Menjalani Hemodialisis dengan Depresi pada Klien Gagal Ginjal Kronik. Jurnal Keperawatan Aisiyah, 6(6).

Kemenkes RI. (2017). Ginjal Kronis.

Kurtulus, F. O., Salman, M. Y., Fazlioglu, A., \& Fazlioglu, B. (2017). Effects of Renal Transplantation on Female Sexual Dysfunction: Comparative Study With Hemodialysis and a Control Group. Transplantation Proceedings, 49(9), 2099-2104. https://doi.org/10.1016/j. transproceed.2017.07.014

Manish Rathi, R. R. (2012). Sexual and Gonadal Dysfunction in Chronic Kidney Diseases : Pathophysiology. Indian Journal of Endocrinology and Metabolism, 16(2), 219-219.

Navaneethan S, Vecchio M, Johnson D, et al. (2010). Prevalance and Corellates Self Reported Sxual Dysfunction in CKD:
Meta Analysis of Observational Studies. American Journal of Kidney Diseases, 56(4), 670-685.

Onecia, Benyamin, Sarah L, L. (2019). End Stage Renal Diseases. Statpearls Publishing $L L C$.

Palmer, BF, Clegg, D. (2017). Gonadal Dysfunction in Chronic Kidney diseases. Springer Link, 18, 113-130.

PERNEFRI. (2018). 11th Report Of Indonesian Renal Registry 2018. Irr, 1-46. https:// www.indonesianrenalregistry.org/data/ IRR 2018.pdf

Strippoli, G. F. M., Depression, C., Dysfunction, S., \& Working, H. (2012). Sexual Dysfunction in Women with ESRD Requiring Hemodialysis. 7. https://doi. org/10.2215/CJN.12601211

Vecchio, M., Palmer, S., De Berardis, G., Craig, J., Johnson, D., Pellegrini, F., Nicolucci, A., Sciancalepore, M., Saglimbene, V., Gargano, L., Bonifati, C., Ruospo, M., Navaneethan, S. D., Montinaro, V., Stroumza, P., Zsom, M., Torok, M., Celia, E., Gelfman, R., ... Goro, L. (2012). Prevalence and correlates of erectile dysfunction in men on chronic haemodialysis: A multinational crosssectional study. Nephrology Dialysis Transplantation, 27(6), 2479-2488. https://doi.org/10.1093/ndt/gfr635

Webster, A. C., Nagler, E. V., Morton, R. L., \& Masson, P. (2017). Chronic Kidney Disease. The Lancet, 389(10075), 12381252. https://doi.org/10.1016/S01406736(16)32064-5 
